\title{
Article \\ Label-Free, Rapid and Facile Gold-Nanoparticles-Based Assay as a Potential Spectroscopic Tool for Trastuzumab Quantification
}

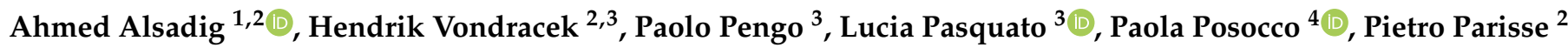 \\ and Loredana Casalis ${ }^{2, *}$ \\ 1 Department of Physics, University of Trieste, 34127 Trieste, Italy; ahmed.mohammed@elettra.eu \\ 2 NanoInnovation Lab, Elettra Sincrotrone Trieste S.C.p.A., 34149 Trieste, Italy; \\ hendrik.vondracek@elettra.eu (H.V.); parisse@iom.cnr.it (P.P.) \\ 3 Department of Chemical and Pharmaceutical Sciences, University of Trieste, 34127 Trieste, Italy; \\ ppengo@units.it (P.P.); lpasquato@units.it (L.P.) \\ 4 Department of Engineering and Architecture, University of Trieste, 34127 Trieste, Italy; \\ paola.posocco@dia.units.it \\ * Correspondence: loredana.casalis@elettra.eu
}

check for updates

Citation: Alsadig, A.; Vondracek, H.; Pengo, P.; Pasquato, L.; Posocco, P.; Parisse, P.; Casalis, L. Label-Free, Rapid and Facile Gold-Nanoparticles -Based Assay as a Potential Spectroscopic Tool for Trastuzumab Quantification. Nanomaterials 2021, 11, 3181. https://doi.org/10.3390/ nano11123181

Academic Editor: Jose L. Arias

Received: 8 October 2021

Accepted: 20 November 2021

Published: 24 November 2021

Publisher's Note: MDPI stays neutral with regard to jurisdictional claims in published maps and institutional affiliations.

Copyright: (c) 2021 by the authors. Licensee MDPI, Basel, Switzerland. This article is an open access article distributed under the terms and conditions of the Creative Commons Attribution (CC BY) license (https:/ / creativecommons.org/licenses/by/ $4.0 /)$.

\begin{abstract}
Monoclonal antibody-based immunotherapy is one of the pillars of cancer treatment. However, for an efficient and personalized approach to the therapy, a quantitative evaluation of the right dose for each patient is required. In this study, we developed a simple, label-free, and rapid approach to quantify Trastuzumab, a humanized IgG1 monoclonal antibody used against human epidermal growth factor receptor 2 (HER2), overexpressed in breast cancer patients, based on localized surface plasmon resonance (LSPR). The central idea of this work was to use gold nanoparticles (AuNPs) as plasmonic scaffolds, decorated with HER2 binders mixed with oligoethylene glycol (OEG) molecules, to tune the surface density of the attached macromolecules and to minimize nonspecific binding events. Specifically, we characterized and optimized a self-assembled monolayer of mixed alkylthiols terminated with nitrilotriacetic acid (NTA), and OEG3 as a spacing ligand to achieve both excellent dispersibility and high reliability in protein immobilization. The successful immobilization of histidine-tagged HER2 (His-tagged HER2) on NTA via cobalt (II) chelates was demonstrated, confirming the fully functional attachment of the proteins to the AuNP surface. The proposed design demonstrates the capability of producing a clear readout that enables the transduction of a Trastuzumab/HER2 binding event into optical signals based on the wavelength shifts in LSPR, which allowed for detecting clinically relevant concentrations of Trastuzumab down to $300 \mathrm{ng} / \mathrm{mL}$ in the buffer and $2 \mu \mathrm{g} / \mathrm{mL}$ in the diluted serum. This strategy was found to be fast and highly specific to Trastuzumab. These findings make the present platform an auspicious tool for developing affordable bio-nanosensors.
\end{abstract}

Keywords: localized surface plasmon resonance (LSPR); functionalized AuNPs; Co(II)NTA; selfassembled monolayer (SAM); HER2/neu receptor; Trastuzumab; biosensing

\section{Introduction}

Trastuzumab (commercialized as Herceptin ${ }^{\mathrm{TM}}$ ) is a humanized Immunoglobulin G1 (IgG1) monoclonal antibody that binds to the extracellular domain (ECD) of human epidermal growth factor receptor 2 (HER2) [1]. HER2 or ErbB2 (Neu) belongs to the receptor tyrosine-specific protein kinase family consisting of four epidermal growth factor receptors (EGFRs): (ErbB1), ErbB2 (Neu), ErbB3, and ErbB4 that regulate different biological processes like cell proliferation, migration, and differentiation [2,3]. When normally expressed, the HER2 pathway regulates cell growth and division. HER2 overexpression (up to 100 times), dimerization, and ECD-HER2 shedding have been observed in many types of cancer. Hence, HER2 is considered a cancer biomarker associated with aggressive forms 
of the disease and poor clinical prognosis [4]. In 1998, the Food and Drug Administration (FDA) approved the use of Trastuzumab in immunotherapy due to its potential inhibitory function to increase the overall survival in HER2-overexpressed metastatic cancers such as gastric and breast cancers [5-7]. Although Trastuzumab has improved the clinical outcomes, several studies have reported an increased risk of cardiac failure in patients who received Trastuzumab in combination with chemotherapeutic agents $[8,9]$. Recent studies have shown that the concentration of Trastuzumab delivered to patients at the beginning of the course of a treatment has a direct impact on the overall survival [10]. It was demonstrated that Trastuzumab did not show the desired clinical benefit in HER2-positive gastric cancer patients when the effective concentration of Trastuzumab was less than $20 \mu \mathrm{g} / \mathrm{mL}$ in the blood plasma after the first administered dose [11]. At the same time, the pharmacokinetics of Trastuzumab is complicated, since the overexpression of HER2 can vary, and the antibody can also bind to the HER2-ECD that is shed from HER2 into the bloodstream.

Up to now, the quantification of Trastuzumab has remained restricted due to the limited capabilities of the available analytical techniques, which are either laborious or not accessible to all laboratories. For instance, B. Cardinali et al. reported the development of a sandwich ELISA protocol to quantify the Trastuzumab concentration in serum using a peptide that mimics the HER2 epitope [12]. The study demonstrated the ability to detect antibody concentrations from 10 to $180 \mu \mathrm{g} / \mathrm{mL}$ in serum. However, despite the appeal, a commercial production of this peptide does not seem within reach. As an alternative to ELISA, high-performance liquid chromatography (HPLC) coupled to tandem mass spectrometry (MS/MS) was described by C.W.N. Damen et al. The presented assay quantified Trastuzumab from 5 to $40 \mu \mathrm{g} / \mathrm{mL}$ in human serum with accuracies $<20 \%$, which is complex and requires a particular extraction procedure from human serum [13]. Based on that, the development of a simple, cost-effective, and sensitive biosensor to monitor the functionality and the concentration of Trastuzumab is highly needed.

Biosensors that harness the plasmonic properties of noble metal nano-constructs have fascinated researchers and received considerable attention as alternatives to conventional signal transduction modalities [14-16]. Among them, localized surface plasmon resonance (LSPR) sensors, which employ metal nanoparticles (e.g., gold or silver), are increasingly used due to the presence of highly localized electromagnetic fields at the nanoparticle surfaces, which renders them hypersensitive to external environments [17]. Lately, gold nanoparticle (AuNP)-based nanosensor mechanisms are considered a rising hope for fabricating smart sensors [18-20]. Since these nanoparticles possess a high surface-tovolume ratio, any tiny perturbation caused within the surroundings can be verified by a spectral shift of their surface plasmonic band. Another advantage of AuNPs is their robust reactivity with thiolated ligands. This allows for surface functionalization that can be specifically geared to detect targets of interest.

The immobilization of biomolecules, including proteins, on 2D or 3D substrates has become a crucial process to develop biosensors [21,22]. While maintaining the functionality of proteins, directed immobilization can be achieved by using affinity-based techniques between a tag and a biocompatible surface. Nitrilotriacetic acid (NTA)-modified materials is a widely adopted technology for the purification and isolation of histidine (His)-tagged recombinant proteins in the presence of $\mathrm{Ni}^{2+}, \mathrm{Cu}^{2+}$, and $\mathrm{Co}^{2+}$ ions as chelating agents [23-25]. The high affinity of His-tagged protein-NTA interactions and the facile disruption of the complex make NTA highly useful for various applications, including protein purification, labeling, specific immobilization, and the construction of advanced functional materials [26-28].

In this work, we aim to explore the use of AuNPs coated with a self-assembled mixed monolayer (mixed SAM) of NTA-modified and oligoethylene glycol (OEG)-modified alkylthios. The novelty of the present work lies in the particle functionalization strategy (Figure 1) that offers: (1) excellent dispersion stability and proper biorecognition endowed by the mixed SAM containing smaller molecules in comparison with bulky PEGylated 
ligands, (2) the possibility of finely tuning AuNP surface loading to meet the expectation of various bio-applications, and (3) a much faster sample-to-answer LSPR-based plasmonic platform than the lengthy incubation protocols used in ELISA assays. In our design, antibody recognition results in forming a nanoparticle network thanks to the capability of antibodies to link one protein at each arm, leading to plasmonic coupling of the particles that can readily be detected by optical spectroscopy $[29,30]$. Thus, such an optical readout system could be implemented in affordable point-of-care devices to aid personalized therapies or more sophisticated high-throughput clinical analysis settings. As a proof of principle, in this study, we selected the His-tagged HER2 antigen for the selective detection of Trastuzumab.

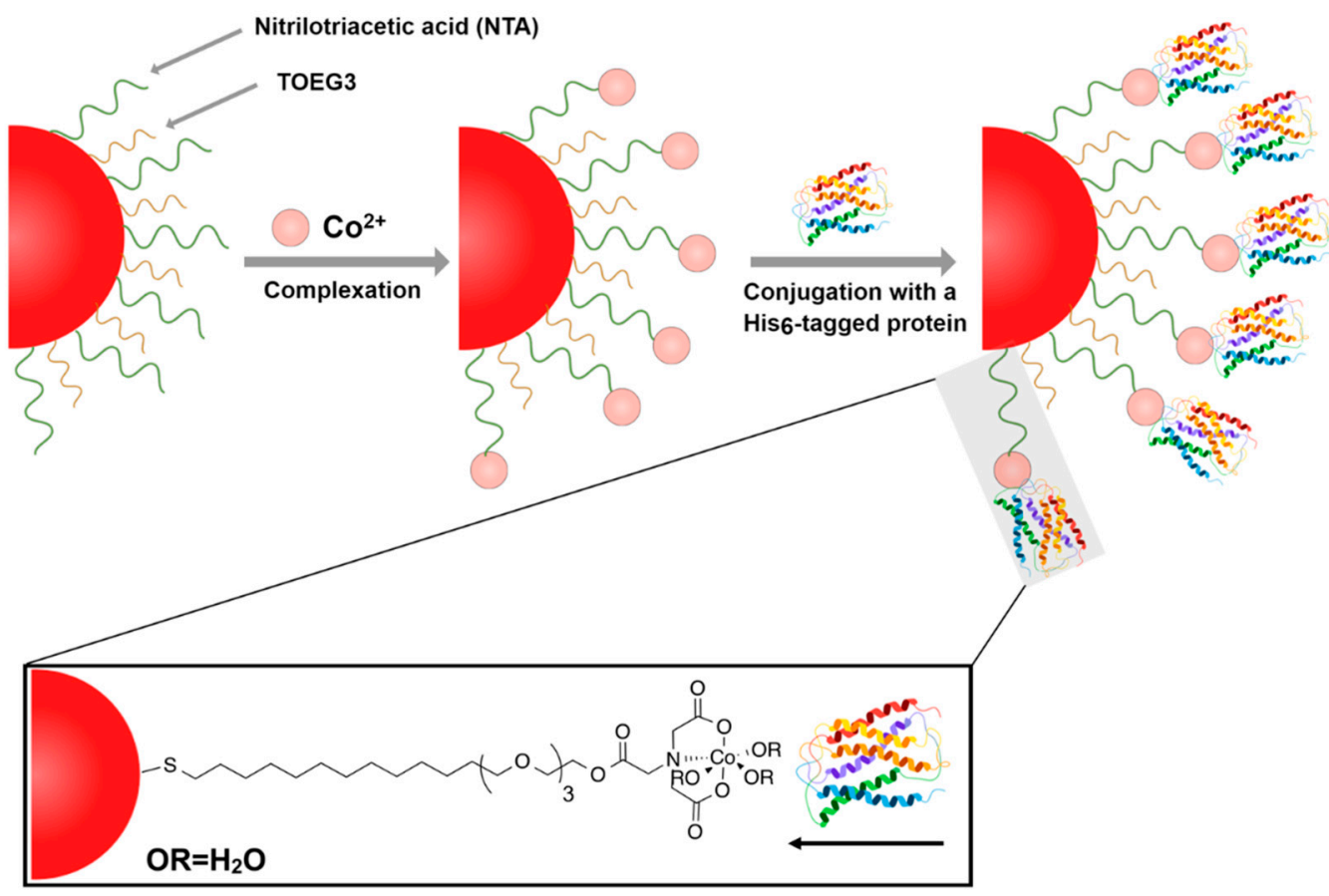

Figure 1. A representation illustrates the attachment strategy of the His-tagged protein onto the surface of the Co(II)NTA/TOEG3 AuNPs.

\section{Materials and Methods}

\subsection{Materials}

A gold (III) chloride solution, Trisodium citrate tribasic dihydrate, Cobalt(II) chloride hexahydrate, and the standard human serum were purchased from Sigma-Aldrich Chemical Co. (St. Louis, MO, USA). (1-mercaptoundec-11-yl)hexa(ethylene glycol) (HS$\left(\mathrm{CH}_{2}\right)_{11}$-EG3OH) and (1-mercaptohexadec-16-yl)tri(ethylene glycol) NTA-terminated (for brevity, TOEG3, and NTA, respectively) were purchased from Prochimia Surfaces (Gdynia, Poland). The human HER2/ErbB2 protein, His-tagged, was purchased from Acro Biosystems (Newark, DE, USA). The monoclonal antibody Trastuzumab was purchased from MedChemExpress (MCE ${ }^{\circledR}$, Monmouth Junction, NJ, USA). The HEPES buffer used in this study was made of 100-mM HEPES buffer containing 0.025\% Tween 20, pH 7.4 prepared in ultrapure water (Milli-Q water). Severe acute respiratory syndrome-2019 novel coronavirus (SARS-CoV-2(2019-Ncov)) spike neutralizing antibody, Anti- RBD Rabbit mAb, was purchased from Sino Biological (Beijing, China) and used as a negative control for the specificity test.

\subsection{Synthesis, Characterization, and Functionalization of AuNPs}

AuNPs of approximately $13 \mathrm{~nm}$ a diameter were synthesized by a sodium citrate reduction of hydrogen tetrachloroaurate $\left(\mathrm{HAuCl}_{4}\right)$ as described elsewhere [31]. Briefly, 
$1.1 \mathrm{~mL}$ of $17.3-\mathrm{mM} \mathrm{HAuCl}_{4}$ was added to $43.6 \mathrm{~mL}$ of Milli-Q water and brought to a boil with vigorous stirring on a magnetic stirrer hotplate. Then, $300 \mu \mathrm{L}$ of $72 \mathrm{mg} / \mathrm{mL}$ of trisodium citrate dihydrate was added rapidly. The solution underwent a color change from yellow to colorless, then dark blue and, finally, deep red within a few minutes. The reaction was maintained at the boiling point for $30 \mathrm{~min}$ to assure the complete reduction of the gold salt; after which, the solution was cooled down to room temperature. The resulting gold colloids were protected from light and stored at $4{ }^{\circ} \mathrm{C}$ until required. The final concentration of the colloid solution was $3.94 \mathrm{nM}$. The optical properties, the morphology, and the hydrodynamic diameter of the AuNPs were verified by Ultraviolet-Visible (UVVis) spectroscopy (Perkin-Elmer lambda 25, Waltham, MA, USA), transmission electron microscopy (TEM) (Philips, Eindhoven, The Netherlands), and dynamic light scattering (DLS) (Malvern Instrument, UK), respectively. The functionalization of AuNPs with NTA and TOEG3-mixed SAM was obtained via a place exchange approach. After determining the minimum concentration of TOEG3 that fully covers the AuNPs, the citrate ligands covering the AuNPs were replaced by NTA and TOEG3 ligands gently mixed at a 50:50 ratio, forming a fully mixed monolayer on the AuNPs by self-assembling overnight at room temperature. Following the protocol described in Reference [19], the particles were purified via centrifugation $(2 \times, 7200 \times g$ for $45 \mathrm{~min})$. The final pellet was redispersed in $500 \mu \mathrm{L}$ of the buffer (100-mM HEPES containing $0.025 \%$ Tween 20, pH 7.4). Successful surface functionalization was confirmed by monitoring the change of the hydrodynamic diameter of particles using DLS, gel electrophoresis, and the characteristic surface plasmon band (SPB) peak before and after the passivation using UV-Vis spectroscopy.

\subsection{Incorporation of $\mathrm{Co}^{2+}$ Cations and Immobilization of Histidine-Tagged HER2 Protein}

Functionalized AuNPs $(450 \mu \mathrm{L}, 2 \mathrm{nM})$ were incubated with $\mathrm{CoCl}_{2}(50 \mu \mathrm{L}, 100 \mathrm{mM})$ for $1 \mathrm{~h}$ at room temperature. After charging with $\mathrm{Co}^{2+}$, the particles were centrifuged $(2 \times, 7200 \times g$ for $30 \mathrm{~min})$ and washed twice with the buffer. Ultimately, the particles were suspended in the same buffer and filtered through a $0.1-\mu \mathrm{m}$ syringe filter. For the protein immobilization onto the particles, $2 \mu \mathrm{L}, 6.3 \mu \mathrm{M}$ of His-tagged HER2 protein (Histagged HER2, 0.1\% BSA in PBS) was introduced to the mixture and left to react at room temperature under mild shaking for $1 \mathrm{~h}$. Following that, the particles were centrifuged $(2 \times, 5000 \times g$ for $20 \mathrm{~min})$ and, finally, redispersed in $500 \mu \mathrm{L}$ of the buffer. Subsequently, the particles were characterized using UV-Vis spectroscopy and DLS.

\subsection{LSPR-Based Detection of Trastuzumab using His-Tagged HER2 Decorated AuNPs}

Trastuzumab antibody at various concentrations ranging from 0.1 to $40 \mu \mathrm{g} / \mathrm{mL}$ was added to His-tagged HER2/ AuNP bioconjugates in a final volume of $500 \mu \mathrm{L}$, wellredispersed, and left to react for $5 \mathrm{~min}$ before conducting the spectroscopic scan. The corresponding absorption spectra were recorded in the wavelength range from 400 to $750 \mathrm{~nm}$. The degree of aggregation was assessed by computing the ratio of the absorption recorded at two selected wavelengths $\left(\mathrm{A}_{600} / \mathrm{A}_{520}\right)$ and normalizing this ratio to the corresponding values before addition of the antibody.

\section{Results and Discussion}

\subsection{Characterization of Synthesized AuNPs}

Most commonly, AuNPs are synthesized using the reduction of the soluble gold salt $\left(\mathrm{HAuCl}_{4}\right)$ in the presence of capping agent such as sodium citrate, a compound able to attach to the nanoparticle surface, preventing its growth beyond the desired size and conferring stability of the colloid in the solvent used. The particle shape and dimensions can be controlled by tuning the experimental parameters, such as the reaction time, temperature, and most importantly, the ratio between the reducing agent used and gold precursor. The UV-Vis spectrum, as shown in Figure S1, of AuNPs synthesized using the citrate reduction method and the corresponding TEM of citrate-capped AuNPs exhibited a maximum absorption at $518 \mathrm{~nm}$, consistent with the typical SPR band of AuNPs. This renders a 
colloidal solution of spherical AuNPs, which is visibly red in color. The TEM in Figure S1 revealed a size distribution of the resulting nanoparticles of $13 \pm 1 \mathrm{~nm}$, while the DLS measurements showed that the particles have an average diameter of $15 \pm 6 \mathrm{~nm}$, which is compatible with the AuNP size considering the hydration shell. The selected diameter size $(13 \mathrm{~nm})$ was based on finding a compromise between having a significant loading of biorecognition sites while maintaining the advantages of the small size.

\subsection{Passivation of AuNPs with NTA/TOEG3 SAM}

The variety of applications of NTA-based technology in the purification, immobilization, and separation of His-tagged macromolecules is unparalleled. The incorporation of the NTA moiety on nanosized particles was reported by $\mathrm{Xu}$ et al., demonstrating the ability of these nanoparticles to chelate to bidentate $\mathrm{Ni}^{2+}$ or $\mathrm{Co}^{2+}$ cations [32]. Later, Chen et al. further employed this strategy by incorporating Ni-NTA onto superparamagnetic particles to enrich His-tagged proteins and other phosphorylated peptides [33]. Sosibo et al. reported the synthesis of stable, hydrophilic monolayer-protected clusters of gold (Au-MPCs) functionalized with PEG-NTA and co-stabilized with PEG-OH as probes for targeting histidine-tagged proteins [34]. It was demonstrated that it is crucial to incorporate a spacing ligand, forming a mixed monolayer onto the particle surface to enhance the long-term stability of NTA-functionalized nanoparticles. However, long PEGylated alkylthiol might hinder the plasmonic effect we would like to exploit for high sensitivity biorecognition. In the present study, in a single-step reaction, the shorter NTA/TOEG3 were made self-assembling onto AuNPs via the ligand place exchange approach of the loosely bound citrates capping the colloidal surface. TOEG3 was chosen as the spacing ligand due to its high hydrophilicity that promotes favorable interactions with the gold colloids. Besides, TOEG3 acts as a protein-repellent thiol, reducing the risk of the nonspecific adsorption of biomolecules onto AuNP surfaces, as already demonstrated in our group on flat Au surfaces [35]. In previous studies on AuNPs, however, it was reported that short-chain OEG thiols with $\leq 4$ EG units can stabilize only a suspension of small AuNPs $(<3 \mathrm{~nm})$. For larger AuNPs $(>10 \mathrm{~nm})$, OEG thiols $<6 \mathrm{EG}$ units were found to be insufficient to stabilize the colloids [36]. Contrastingly, from our UV-Vis absorption measurements reported in Figure 2a, we found that, starting from the concentration of $5 \mu \mathrm{M}$, TOEG3 successfully prevented a 2-nM solution of 13-nm diameter AuNPs from aggregation. In this condition, we assumed a fully covered SAM was formed on the nanoparticle. As a starting point for the formation of mixed, functional SAM, we then used a 50:50 concentration of NTA and TOEG3-terminated alkylthiols and $2.5 \mu \mathrm{M}$ of NTA plus $2.5 \mu \mathrm{M}$ of TOEG3 to form a homogenous and stable mixed SAM onto the AuNP surface. The successful ligands attachment was confirmed by the 3-nm redshift in the UV-Vis spectrum, as shown in Figure 2b. Gel electrophoresis revealed a slower mobility of NTA/TOEG3 than only NTA (see Figure $2 b$ for the discrepancy)-coated particles, indicating surface modification of the particles towards the formation of a mixed monolayer of the dissimilar ligands that are covalently bonded to AuNP surfaces. This finding also demonstrates the potential of agarose gel electrophoresis to confirm the SAM formation of charged SAMs on the surfaces of the AuNPs. 

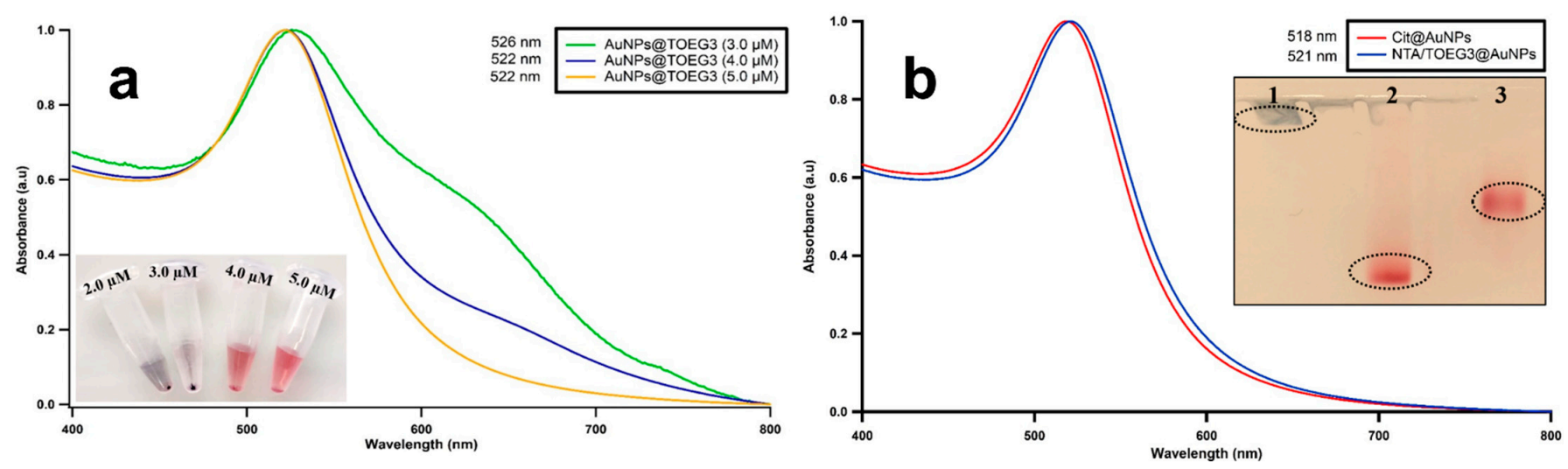

Figure 2. (a) UV-Vis absorption spectra of AuNPs coupled with different concentrations of TOEG3. The blue color indicated that the TOEG3 was insufficient to cover the surfaces of particles. Once a sufficient amount was used, the colloidal solution does not form agglomerates, and the red color is maintained. (b) UV-Vis spectra of citrate and SAM-protected AuNPs to monitor the surface modification. Inset: Gel electrophoresis bands for: (1) citrate-capped AuNPs, (2) NTA@AuNPs, and (3) NTA/TOEG3@AuNPs.

\subsection{Incorporation of $\mathrm{Co}^{2+}$ ations and Immobilization of the His-Tagged HER2 Protein}

To detect Trastuzumab, the His-tagged HER2 protein was first anchored on the AuNPs surface based on the Co(II)-NTA complexation strategy depicted in Figure 1. The quadridentate NTA ligand occupies four coordination positions on the hexadentate central cobalt cation, allowing for the availability of the two vacant binding sites for the His-tagged biomolecules to attach. Following the reaction of the modified AuNPs with excess $\mathrm{CoCl}_{2}$, there was no observable change in the optical properties of the particles, as verified by $\mathrm{UV}-\mathrm{Vis}$ spectroscopy. It is noteworthy that controlling the reaction time and the concentration of $\mathrm{CoCl}_{2}$ is crucial to prevent any agglomeration of the particles. When the $\mathrm{Co}^{2+}$ concentration is high, particles form visible aggregation during the purification process, likely because of the formation of polynuclear Co-NTA complexes instead of well-defined mononuclear ones that may trigger NP aggregation, while, if the $\mathrm{Co}^{2+}$ concentration is too low, there are not enough ions on the particles to conjugate enough proteins on the particle surface. However, in our study, incubating with $10 \mathrm{mM}$ of $\mathrm{CoCl}_{2}$ for $1 \mathrm{~h}$ was ideal to charge the particles without causing any agglomeration. Upon the introduction of the His-tagged HER2 protein, the resultant bioconjugates were readily soluble in the solvent buffer and showed the typical red color of the gold colloids. While the UV-Vis absorption spectra remained identical to that of the NTA/TOEG3-modified particles spectrum, the DLS readouts confirmed the successful functionalization upon each step of preparation (Figure 3). This is not surprising, given the different principles of both techniques. Whereas UV-Vis spectrophotometry relies on detecting changes in the optical properties reflected in LSPR, DLS can reveal differences in the particle hydrodynamic diameter size upon functionalization that do not necessarily cause observable variations in the overall optical properties. 


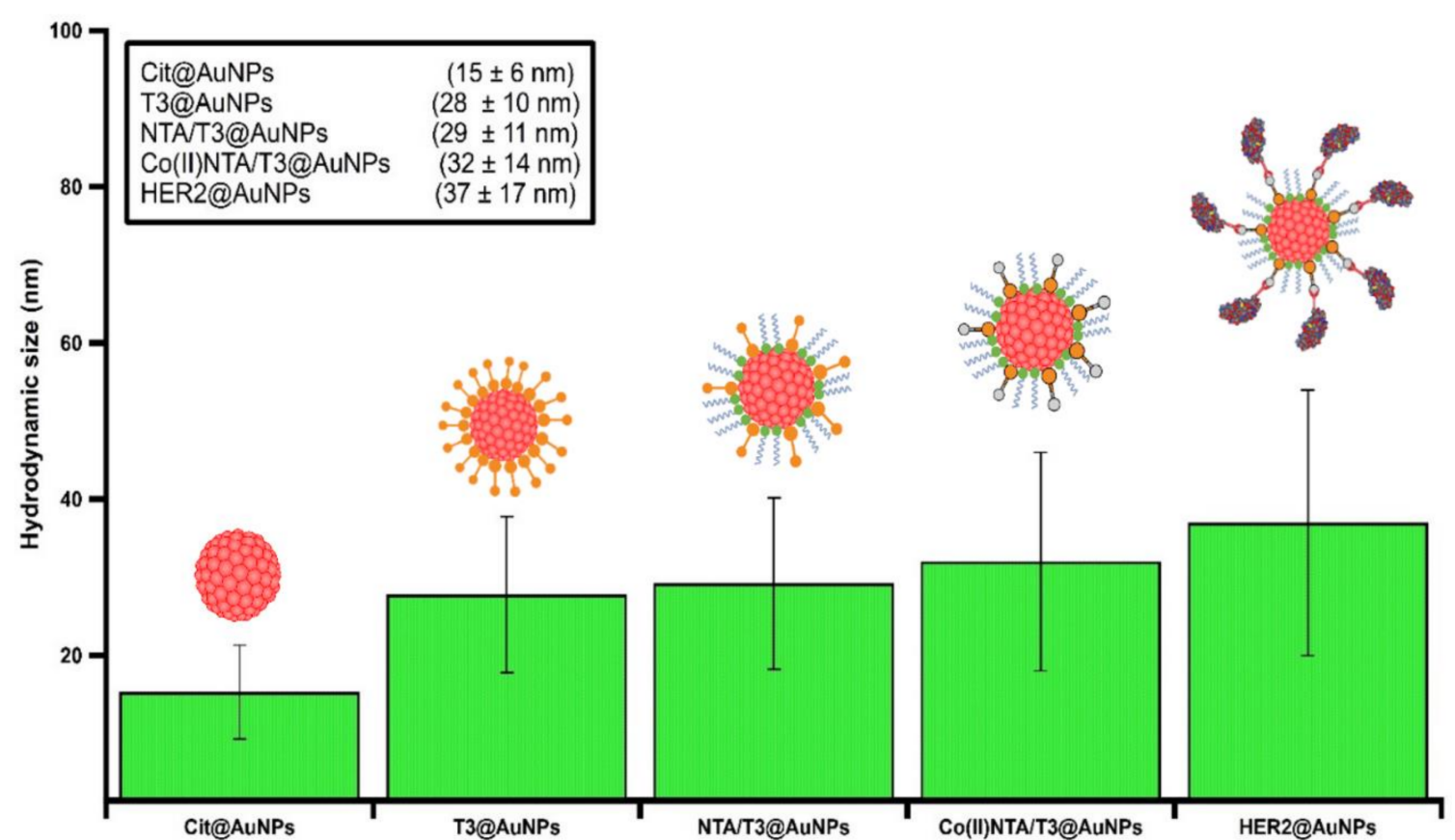

Figure 3. Volume-weighted size distribution DLS measurements of AuNPs after different steps of the preparation.

\subsection{Detection of Trastuzumab by LSPR in Buffer}

After demonstrating that Trastuzumab binds to the His-tagged HER2 protein receptor using indirect ELISA (details in Figure S2), the sensing capability of our platform was then tested by monitoring the LSPR shifts induced by the immunoconjugate recognition across a wide range of Trastuzumab concentrations $(0.1-40 \mu \mathrm{g} / \mathrm{mL})$, physiologically relevant in anti-HER2 cancer treatment, in 100-mM HEPES buffer containing 0.025\% Tween 20 ( $\mathrm{pH} 7.4$ ). The range tested here covers the therapeutic relevant range of 5-40 $\mu \mathrm{g} / \mathrm{mL}$, i.e., the range of concentrations of circulating Trastuzumab in the blood used to dose the therapy in a personalized manner [37]. The LSPR peak of AuNP depends on the geometry, surface chemistry, and the refractive index of the surrounding environment [38]. Nanomaterials that exhibit high refractive index sensitivities are strongly desired for fabricating plasmonic nanosensors. Herein, it was expected that shifts in LSPR would be dependent on the amount of antibody bound to antigen-decorated particles. As clearly observable from Figure S3, the LSPR undergoes a redshift upon the addition of a concentration of at least $1.3 \mu \mathrm{g} / \mathrm{mL}$ of Trastuzumab. Increasing concentrations of the antibody led to a more substantial redshift of the LSPR band due to the binding of the immunoconjugate. A similar trend was also observed in previous studies [39-41]. Generally, the LSPR spectral shifts are attributed to the combination of local refractive index changes induced by analyte adsorbed onto the particle surface and the coupling of surface plasmons of adjacent particles. The latter heavily depends on multiple interactions between the ligands and target receptors. In the present case, the significant redshift presumably corresponds to the interparticle coupling of surface plasmons due to the presence of Trastuzumab. It shall be mentioned that the absorbance measurements were taken $5 \mathrm{~min}$ after completing the titration process for the respective amount of the antibody. The timeframe required in this step of biorecognition, especially in comparison to the lengthy incubation protocols used in ELISA assays, highlights the utility of this platform for the development of a rapid LSPR-based plasmonic nanosensor. The shift in LSPR as a function of Trastuzumab concentration was quantified as shown in Figure 4 (blue dots). Additionally, the normalized ratio of the absorbance at $600 \mathrm{~nm}\left(\mathrm{~A}_{600}\right)$ and at $520 \mathrm{~nm}\left(\mathrm{~A}_{520}\right)$ with respect to the antibody concentration was determined. This relation reveals the arrangement of the particles in the assay suspension. Whereas the former is related to the wavelength at which aggregation is observed, the latter corresponds to the LSPR absorption peak of unperturbed AuNPs. 
Normalization to the absorbance value displayed by the nanoparticles decorated with His-tagged HER2 enables us to quantify NP clusterization: the higher the ratio, the greater the degree of aggregation. The normalized ratio of the aggregation was plotted as a function of the target antibody concentration. Figure 4 (red dots) shows a near-sigmoidal titration curve for the various concentrations used in this study. When a small amount of antibody was added $(300 \mathrm{ng} / \mathrm{mL})$, the aggregation induced resulted in a small rise in the aggregation ratio $(>1)$, presumably due to the onset formation of antibody-mediated dimers. The presence of an increasing quantity of the antibody promotes the aggregation with a monotonic increase of the signal observed between $4 \mu \mathrm{g} / \mathrm{mL}$ and $20 \mu \mathrm{g} / \mathrm{mL}$ before reaching a plateau at a concentration of $40 \mu \mathrm{g} / \mathrm{mL}$ of the target analyte. First, we can conclude that the limit of Trastuzumab detection (LOD) of our assay is as low as $300 \mathrm{ng} / \mathrm{mL}$ by examining the formation assemblies through the aggregation ratio relationship, which gives a more sensitive and a better quantitative description of the particle status with increasing concentrations of the target analyte. Moreover, the saturation is reached at $40 \mu \mathrm{g} / \mathrm{mL}$, which is the limit of the clinically relevant concentrations of antibody freely circulating in the blood in Trastuzumab-based therapy. To further validate this result, TEM micrographs were acquired, shown in Figure 5a-d, displaying the morphology of the His-tagged HER2-decorated particles before and after the addition of Trastuzumab $(2,10$, and $20 \mu \mathrm{g} / \mathrm{mL})$ (see, also, Figure S4). The findings demonstrate that the capture of antibodies leads to a decrease in the interparticle distance and, subsequently, leads to cluster formation, enabling us to develop a rapid sensing platform using a simple UV-Vis spectrophotometer. The DLS readouts further confirmed our observations by detecting the clusterization of AuNPs induced by the Trastuzumab in the assay solution. As shown in Figure 5e, the average hydrodynamic diameter of His-tagged HER2-decorated AuNPs was greatly increased from $37 \mathrm{~nm}$ to $265,528,747,837$, and $923 \mathrm{~nm}$ upon binding to Trastuzumab with concentrations ranging from 2 to $10 \mu \mathrm{g} / \mathrm{mL}$, respectively, indicating that the modified AuNPs were agglutinated together into aggregates.

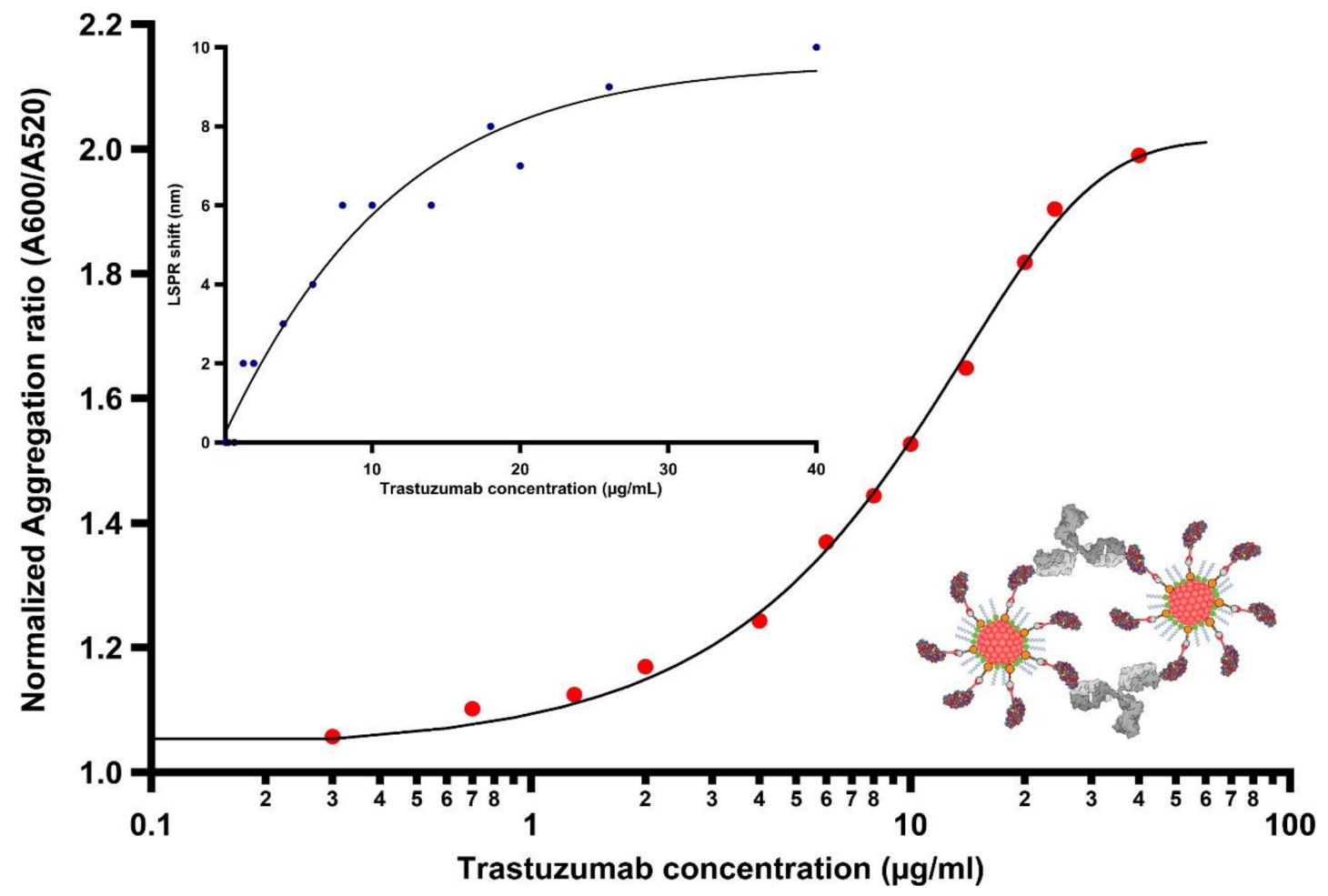

Figure 4. Quantification of the LSPR shift (blue dots) and normalized aggregation ratio (red dots) of immunoconjugates with various concentrations of Trastuzumab. Dose-response presented in each plot was fitted with the four-parameter logistic sigmoidal curve. 

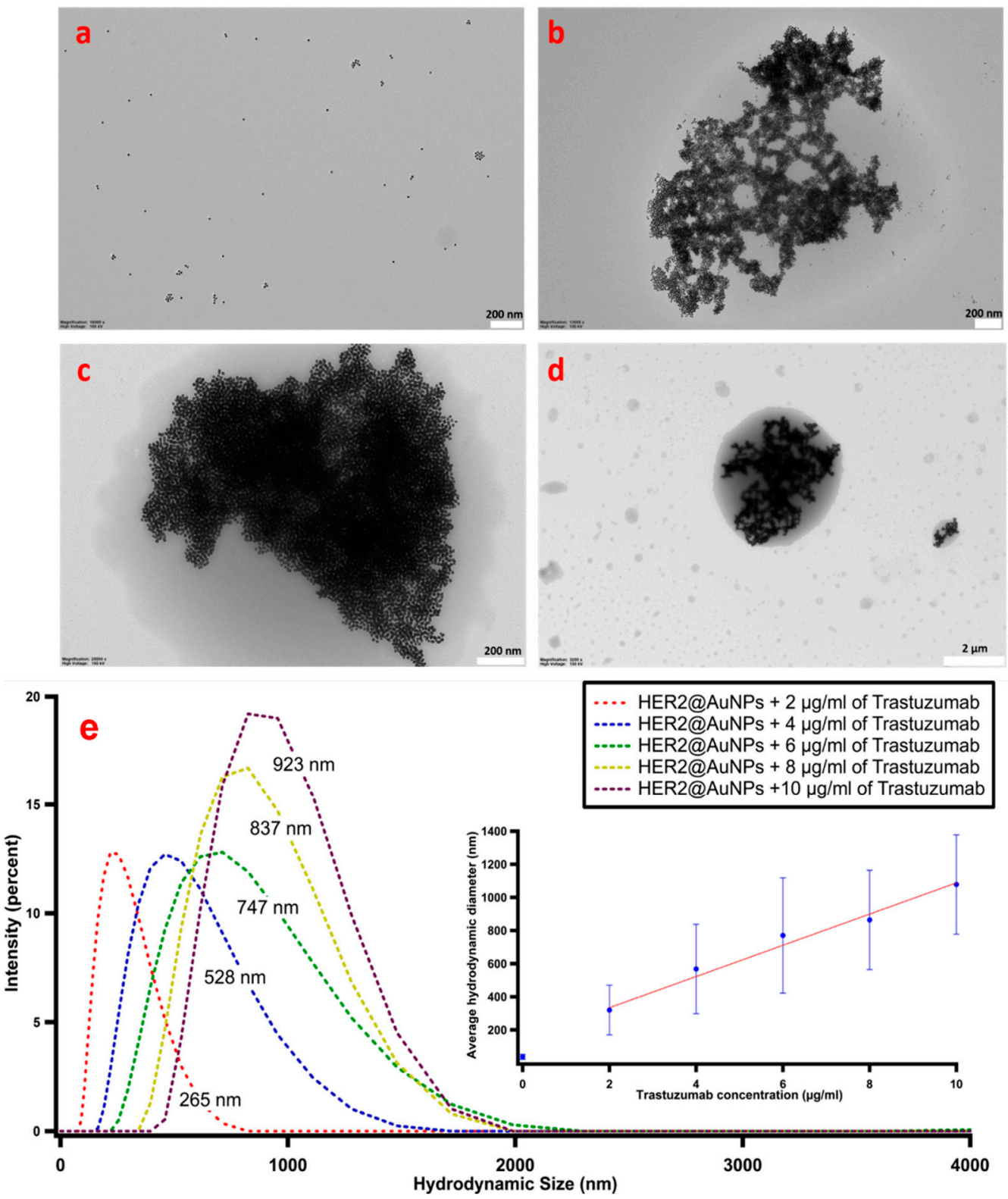

Figure 5. (a-d) Representative TEM images of (a) HER2-decorated AuNPs (b-d) incubated with 2, 10 , and $20 \mu \mathrm{g} / \mathrm{mL}$ of Trastuzumab. The formation of a 3D network indicates the successful coupling of AuNPs through Trastuzumab linking. (e) DLS readouts for AuNPs probes treated with various concentrations of Trastuzumab. Upon mixing the HER2-decorated AuNP probes with Trastuzumab, the particles are clustered together, leading to an average particle size increase of the assay solution.

\subsection{Evaluating the Specificity of the Platform}

Having tested the concentration-dependent LSPR shifts of His-tagged HER2-decorated particles over a wide range of Trastuzumab concentrations, the next step was to evaluate the specificity of the platform. In this case, we used a non-HER2-specific antibody, Anti-RBD, to interact with the particles instead of Trastuzumab, using the same method to observe if any assembly would form. As expected, upon incubation with various concentrations of off-target antibodies, no change in the UV-Vis absorption spectra was observed (Figure S5), indicating that the particles sensed no or negligible interactions. These findings demonstrate the high specificity of our platform for detecting Trastuzumab. 


\subsection{Elucidating the Impact of Free His-Tagged HER2 Proteins on LSPR Response}

To acquire a deeper understanding about the role played by the free His-tagged HER2 proteins in the LSPR response, we devised an experiment in which a dispersion of the bioconjugates was treated with increasing amounts of free His-tagged HER2 prior to the addition of a fixed concentration of Trastuzumab $(10 \mu \mathrm{g} / \mathrm{mL})$. As can clearly be seen in Figure S6, an increasing amount of the proteins caused a dramatic drop in the normalized ratio $\left(\mathrm{A}_{600} / \mathrm{A}_{520}\right)$, indicating a marginal aggregation of the nanoparticles. Interestingly, nearly $5 \mathrm{nM}$ of free HER2 protein in the colloidal suspension was sufficient to cause a drastic drop in the normalized ratio $\left(\mathrm{A}_{600} / \mathrm{A}_{520}\right)$. This implies that all antigen-binding recognition sites of the antibody were saturated and no longer accessible for bridging His-tagged HER2 immobilized on decorated AuNPs. Thus, our analysis indicates the importance of removing unbound proteins after the conjugation process with Co(II) NTA.

\subsection{Evaluating the LSPR Response upon Tuning the Density of the Surface Grafted SAM}

To investigate the possibility of optimizing the density of the His-tagged HER2 protein immobilized onto the particle surface, we varied the molar ratio of the NTA anchor and the TOEG3 spacer ligands up to the saturation density. The coating densities were adjusted by using the 20:80, 50:50, and 80:20 ratios between NTA and TOEG3, respectively. At first glance, Figure 6 shows that the aggregation ratio measured with UV-Vis gradually increases for the various AuNP-Trastuzumab immunocomplexes when the amount of NTAligand increases. AuNPs passivated with increasing NTA-coating density also revealed a gradual increase in the hydrodynamic size, indicating a higher protein loading capacity. However, we observed that, with a 80:20 coverage density, the chance of having aggregates after protein loading is relatively high (see Figure S7), likely because there are still $\mathrm{Co}^{2+}$ ions bound to the NP surface. Thus, the chance for electrostatic interactions with other NTA-terminated AuNPs is increased. Therefore, we maintained a 50:50 ratio for the rest of the study.

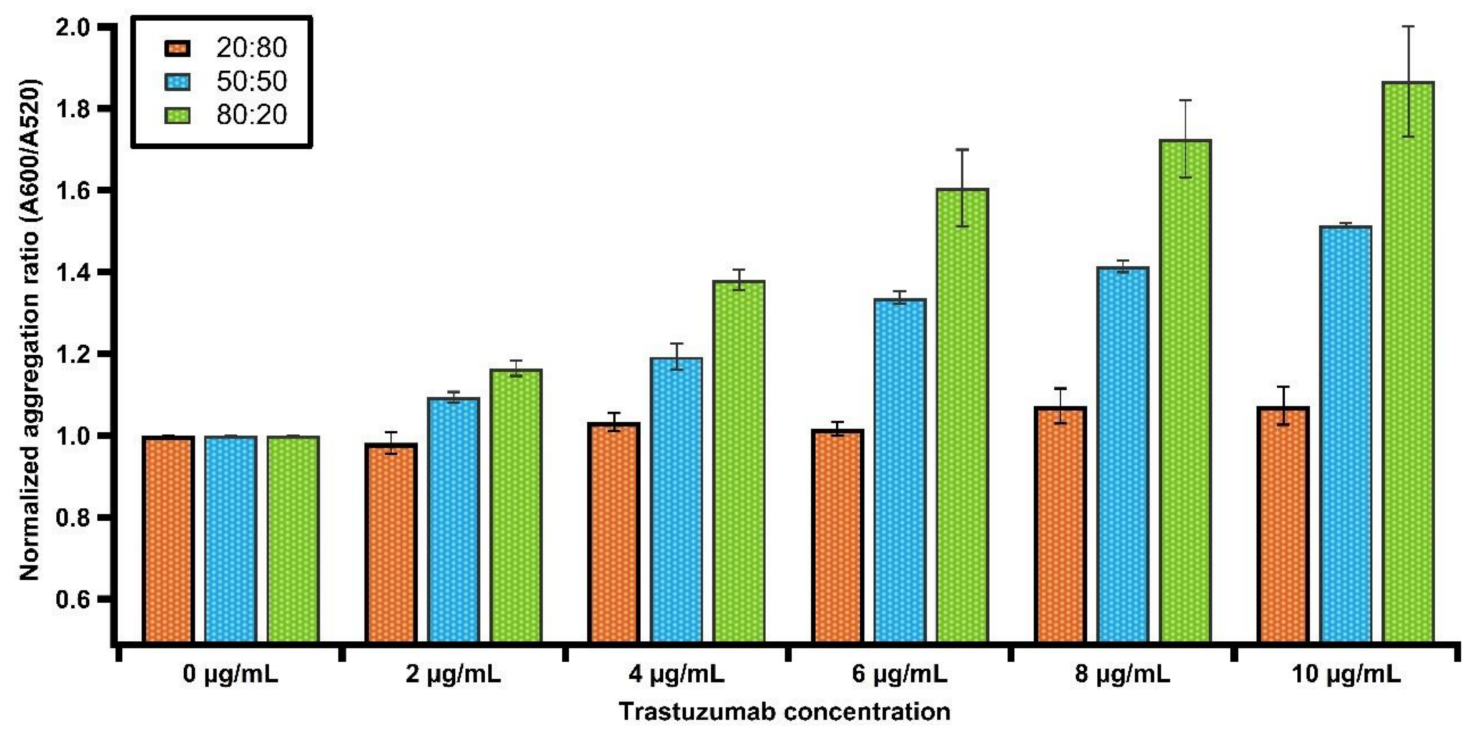

Figure 6. Comparison of the LSPR response for various concentrations of Trastuzumab upon adjusting the SAM density on the surfaces of AuNPs. Note that, with a 20:80 ratio, no plasmonic response was observed across all doses of the antibody.

\subsection{Evaluating Assessment of Trastuzumab detection by LSPR in Human serum}

At this stage, we investigated the biosensor performance in detecting trastuzumab in a complex matrix, such as human serum. Solutions containing His-tagged HER2-decorated particles were incubated with a range of diluted human serum $(100,75,50,25$, and $10 \times)$ containing Trastuzumab $(2,10$, and $20 \mu \mathrm{g} / \mathrm{mL})$ to show the results of direct detection in diluted human serum. As seen in Figure 7, it is highly challenging to detect Trastuzumab 
in a colloidal suspension containing tenfold diluted serum. This is not surprising, as, in extremely complex biological mixtures, several proteins, including transferrin (TF) or histidine-rich glycoprotein (HRG), are present in high concentrations and can act as interferents [19]. It was reported that the latter highly interacts with several ligands, including metal ions [23]. To verify this possibility, we incubated the bioconjugates in $10 \%$ serum to allow the possible displacement of the His-tagged HER2 protein from the surface. Then, the bioconjugates were separated from the serum and evaluated in an assay with various concentrations of Trastuzumab (in buffer). A shown in Figure S8, no LSPR response was observed across all the doses of Trastuzumab, demonstrating a loss of sensitivity due to less effective conjugates. The presence of histidine-rich proteins that may highly interfere with the conjugation of the immunocomplex was investigated by employing Ni-NTA agarose beads (details in S1.4). Contrastingly, upon the purification trial conducted to remove proteins containing histidine repeats in $1 \%$ and $5 \%$ diluted serums (Figure S9), the shifts in LSPR became more pronounced with the addition of $2 \mu \mathrm{g} / \mathrm{mL}$ of the target antibody, as seen in Figure S10. Additionally, as reported in the same figure, the gel electrophoresis showed a slower mobility for the immunocomplex dispersed in the post-treated $5 \%$ diluted serum, indicating a higher chance for Trastuzumab to recognize His-tagged HER2-decorated particles compared to nontreated serum. These findings are in agreement with the findings of a recent report that demonstrated that 100 times the dilution of the human serum was the optimum for detection using NPs [42]. However, further optimization and the investigation of other possible routes to filter the biological media in order to enhance the sensitivity of the proposed platform are part of ongoing research.

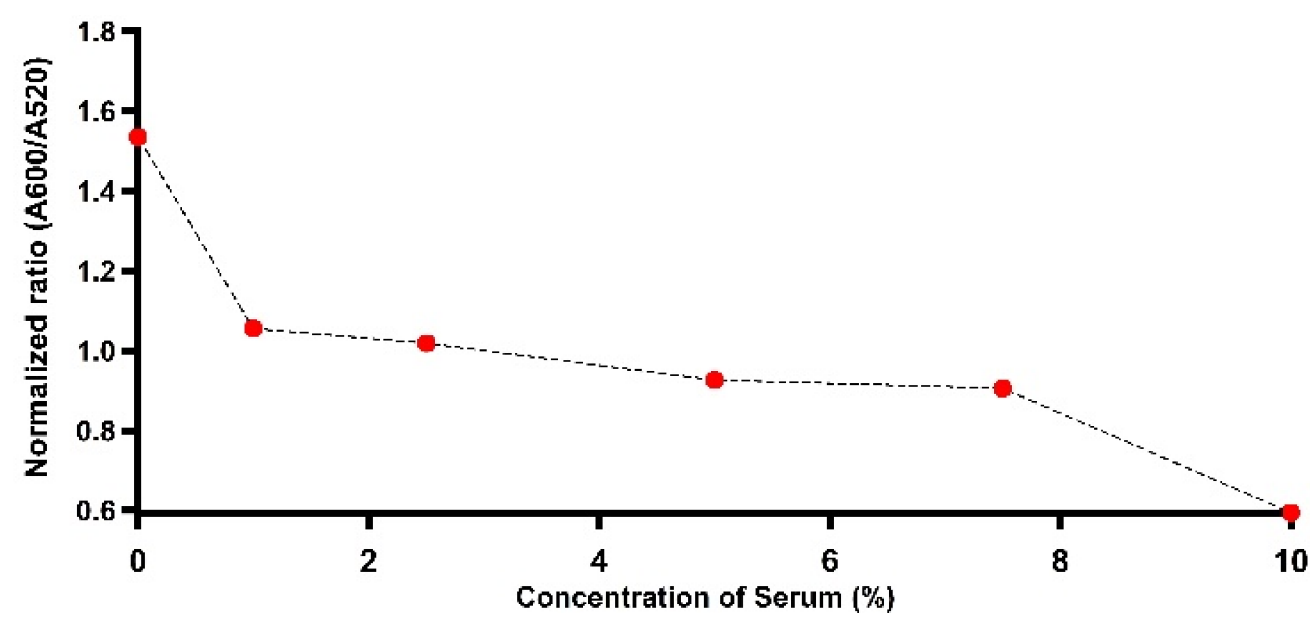

Figure 7. Plasmonic response for His-tagged HER2-decorated particles incubated with various dilutions of human serum-containing Trastuzumab.

\section{Conclusions}

Optical, label-free biosensors represent precious means for real-time, direct analyses of biomolecular interactions that can be exploited to boost the development of precise and individualized therapies for severe diseases like cancer. In this work, we described the development of a facile, rapid, and specific AuNP-based platform for the detection and quantification of Trastuzumab. To accomplish this, the His-tagged HER2 protein was anchored on AuNP surfaces by employing the coordination chemistry of metal complexes attached to a mixed self-assembled monolayer (mixed SAM) onto the nanoparticle surface. We characterized and optimized the Co(II)NTA AuNP platform incorporated with TOEG3 as a spacing ligand for passivating the particle surface to achieve both excellent dispersibility and high reliability in protein immobilization. The successful tethering of the His-tagged HER2 protein was demonstrated, confirming the fully functional attachment of the protein to the Co(II)NTA/TOEG3@AuNP platform. This methodology is readily applicable to other histidine-rich biomolecules. In line with the expectations for this type of 
essay, the biorecognition of antibodies and antigen-decorated AuNP conjugates results in a substantial LSPR shift due to the formation of particle assemblies, enabling the detection of the antibody in clinically relevant concentrations. Although our sensing platform showed a different sensitivity when comparing the buffer and the human serum matrix, with further optimizations and improvements, we anticipate our platform will pave the way for fabricating lab-free and ready-to-use nanoprobes, which may have application potentials in point-of-care medical diagnoses.

Supplementary Materials: The following are available online at https:/ /www.mdpi.com/article/10 $.3390 /$ nano11123181/s1, Figure S1: UV-Vis spectrum of AuNPs synthesized using citrate reduction method and the corresponding TEM micrograph. Red color of the solution confirmed the production of AuNPs. Figure S2: Indirect ELISA analysis performed for Trastuzumab antibody with various concentrations of His-HER2 antigen. Figure S3: UV-Vis absorption spectra for His-HER2 decorated AuNPs before and after the incubation with Trastuzumab. LSPR peaks redshifted upon varying the concentration of the antibody. Figure S4: SEM micrographs of (a) NTA-TOEG3 coated AuNPs, (b) HER2-decorated AuNPs treated with $10 \mu \mathrm{g} / \mathrm{mL}$ Trastuzumab. Note cross-linking of the nanoparticles caused by the addition of the target antibody. Figure S5: UV-Vis absorption spectra for His-HER2 incubated with various concentrations of non-HER2 recognizing antibody. The spectroscopic signal was similar to HER2 capped AuNPs. Figure S6: Spectrophotometric titration ranging from 6-32 nM free His-tagged HER2 concentrations. Figure S7: DLS volume-weighted size distributions comparing AuNPs coated with NTA and TOEG3 SAM with molar ratios of 20:80, 50:50, and 80:20, respectively. Figure S8: The presence of competing Histidine rich proteins that may have interfered and disrupted the bioconjugate leading to the less sensitive complex formation toward the target antibody. Figure S9: SDS-PAGE image of (1) empty lane, (2) 5\% diluted serum, (3) flow through of the serum after incubation with the matrix, $(4,5)$ first and second wash of the matrix, $(6)$ after eluting the Ni-NTA matrix with imidazole, (7) the Ni-NTA matrix. Note that proteins containing Histidine-repeats were released after the elution step. Figure S10: LSPR shifts for the particles treated with various concentration of the target antibody dispersed in $1 \%$ and $5 \%$ filtered serum. The gel electrophoresis photograph revealed a slower mobility for the immunocomplex hosted by filtered diluted serum.

Author Contributions: Conceptualization, P.P. (Pietro Parisse) and L.C.; methodology, A.A., H.V, P.P. (Pietro Parisse) and L.C.; validation, P.P. (Paolo Pengo), L.P., P.P. (Pietro Parisse) and L.C.; formal analysis, A.A. and H.V.; investigation, A.A.; resources, P.P. (Paolo Pengo), L.P., P.P. (Paola Posocco) and L.C.; writing —original draft preparation, A.A.; writing-review and editing, H.V., P.P. (Paolo Pengo), L.P., P.P. (Paola Posocco) and L.C.; visualization, A.A. and L.C., supervision, P.P. (Pietro Parisse) and L.C.; and funding acquisition, L.C. All authors have read and agreed to the published version of the manuscript.

Funding: This work was partially supported by the MIUR-SIR grant to P.Po. entitled "Structure and function at the nanoparticle biointerface" (RBSI14PBC6).

Acknowledgments: The authors gratefully acknowledge Marta Semrau, Manil Kanade, and Giuseppe Cortone (Structural Biology Laboratory at Elettra Sincrotrone Trieste) for kindly assisting in the gel electrophoretic experiments and ELISA assay.

Conflicts of Interest: The authors declare no conflict of interest.

\section{References}

1. Dziawer, Ł.; Majkowska-Pilip, A.; Gaweł, D.; Godlewska, M.; Pruszyński, M.; Jastrzębski, J.; Wąs, B.; Bilewicz, A. Trastuzumabmodified gold nanoparticles labeled with 211At as a prospective tool for local treatment of HER2-positive breast cancer. Nanomaterials 2019, 9, 632. [CrossRef] [PubMed]

2. Mitri, Z.; Constantine, T.; O'Regan, R. The HER2 receptor in breast cancer: Pathophysiology, clinical use, and new advances in therapy. Chemother. Res. Pract. 2012, 2012, 7. [CrossRef]

3. Casalini, P.; Iorio, M.V.; Galmozzi, E.; Ménard, S. Role of HER receptors family in development and differentiation. J. Cell. Physiol. 2004, 200, 343-350. [CrossRef] [PubMed]

4. Labidi, S.; Mejri, N.; Lagha, A.; Daoud, N.; El Benna, H.; Afrit, M.; Boussen, H. Targeted therapies in HER2-overexpressing metastatic breast cancer. Breast Care 2016, 11, 418-422. [CrossRef] [PubMed]

5. Hudis, C.A. Trastuzumab-Mechanism of action and use in clinical practice. N. Engl. J. Med. 2007, 357, 39-51. [CrossRef] 
6. Orlova, A.; Wållberg, H.; Stone-Elander, S.; Tolmachev, V. On the selection of a tracer for PET imaging of HER2-expressing tumors: Direct comparison of a 124I-labeled affibody molecule and trastuzumab in a murine xenograft model. J. Nucl. Med. 2009, 50, 417-425. [CrossRef]

7. Nahta, R.; Takahashi, T.; Ueno, N.T.; Hung, M.-C.; Esteva, F.J. P27kip1 down-regulation is associated with trastuzumab resistance in breast cancer cells. Cancer Res. 2004, 64, 3981-3986. [CrossRef]

8. Ewer, M.S.; Gibbs, H.R.; Swafford, J.; Benjamin, R.S. Cardiotoxicity in patients receiving Transtuzumab (Herceptin): Primary toxicity, synergistic or sequential stress, or surveillance artifact? Semin. Oncol. 1999, 26, 96-101.

9. Jerusalem, G.; Lancellotti, P.; Kim, S.-B. HER2+ breast cancer treatment and cardiotoxicity: Monitoring and management. Breast Cancer Res. Treat. 2019, 177, 237-250. [CrossRef]

10. González García, J.; Gutiérrez Nicolás, F.; Ramos Díaz, R.; Nazco Casariego, G.J.; Viña Romero, M.M.; Llabres Martinez, M.; Llanos Munoz, M.; Batista Lopez, J.N.; Jiménez Sosa, A.; Ceballos Lenza, I. Pharmacokinetics of trastuzumab after subcutaneous and intravenous administration in obese patients. Ann. Pharmacother. 2020, 54, 775-779. [CrossRef]

11. Cosson, V.F.; Ng, V.W.; Lehle, M.; Lum, B.L. Population pharmacokinetics and exposure-response analyses of trastuzumab in patients with advanced gastric or gastroesophageal junction cancer. Cancer Chemother. Pharmacol. 2014, 73, 737-747. [CrossRef] [PubMed]

12. Cardinali, B.; Lunardi, G.; Millo, E.; Armirotti, A.; Damonte, G.; Profumo, A.; Gori, S.; Iacono, G.; Levaggi, A.; Del Mastro, L. Trastuzumab quantification in serum: A new, rapid, robust ELISA assay based on a mimetic peptide that specifically recognizes trastuzumab. Anal. Bioanal. Chem. 2014, 406, 4557-4561. [CrossRef] [PubMed]

13. Damen, C.W.; Derissen, E.J.; Schellens, J.H.; Rosing, H.; Beijnen, J.H. The bioanalysis of the monoclonal antibody trastuzumab by high-performance liquid chromatography with fluorescence detection after immuno-affinity purification from human serum. $J$. Pharm. Biomed. Anal. 2009, 50, 861-866. [CrossRef] [PubMed]

14. Cetin, A.E.; Coskun, A.F.; Galarreta, B.C.; Huang, M.; Herman, D.; Ozcan, A.; Altug, H. Handheld high-throughput plasmonic biosensor using computational on-chip imaging. Light: Sci. Appl. 2014, 3, e122. [CrossRef]

15. Kailasa, S.K.; Koduru, J.R.; Desai, M.L.; Park, T.J.; Singhal, R.K.; Basu, H. Recent progress on surface chemistry of plasmonic metal nanoparticles for colorimetric assay of drugs in pharmaceutical and biological samples. TrAC Trends Anal. Chem. 2018, 105, 106-120. [CrossRef]

16. Tseng, S.-Y.; Li, S.-Y.; Yi, S.-Y.; Sun, A.Y.; Gao, D.-Y.; Wan, D. Food quality monitor: Paper-based plasmonic sensors prepared through reversal nanoimprinting for rapid detection of biogenic amine odorants. ACS Appl. Mater. Interfaces 2017, 9, 17306-17316. [CrossRef] [PubMed]

17. Anker, J.N.; Hall, W.P.; Lyandres, O.; Shah, N.C.; Zhao, J.; Van Duyne, R.P. Biosensing with plasmonic nanosensors. In Nanoscience and Technology: A Collection of Reviews from Nature Journals; World Scientific: Singapore, 2010; pp. 308-319.

18. Jin, R.; Wu, G.; Li, Z.; Mirkin, C.A.; Schatz, G.C. What controls the melting properties of DNA-linked gold nanoparticle assemblies? J. Am. Chem. Soc. 2003, 125, 1643-1654. [CrossRef]

19. Swartz, J.D.; Gulka, C.P.; Haselton, F.R.; Wright, D.W. Development of a histidine-targeted spectrophotometric sensor using Ni (II) NTA-functionalized Au and Ag nanoparticles. Langmuir 2011, 27, 15330-15339. [CrossRef]

20. Ventura, B.D.; Cennamo, M.; Minopoli, A.; Campanile, R.; Censi, S.B.; Terracciano, D.; Portella, G.; Velotta, R. Colorimetric test for fast detection of SARS-CoV-2 in nasal and throat swabs. ACS Sensors 2020, 5, 3043-3048. [CrossRef]

21. Mohamad, N.R.; Marzuki, N.H.C.; Buang, N.A.; Huyop, F.; Wahab, R.A. An overview of technologies for immobilization of enzymes and surface analysis techniques for immobilized enzymes. Biotechnol. Biotechnol. Equip. 2015, 29, 205-220. [CrossRef]

22. Rusmini, F.; Zhong, Z.; Feijen, J. Protein immobilization strategies for protein biochips. Biomacromolecules 2007, 8, 1775-1789. [CrossRef]

23. Terpe, K. Overview of tag protein fusions: From molecular and biochemical fundamentals to commercial systems. Appl. Microbiol. Biotechnol. 2003, 60, 523-533. [CrossRef] [PubMed]

24. Mori, S.; Takahashi, H.K.; Yamaoka, K.; Okamoto, M.; Nishibori, M. High affinity binding of serum histidine-rich glycoprotein to nickel-nitrilotriacetic acid: The application to microquantification. Life Sci. 2003, 73, 93-102. [CrossRef]

25. Mori, S.; Shinohata, R.; Renbutsu, M.; Takahashi, H.K.; Fang, Y.-I.; Yamaoka, K.; Okamoto, M.; Yamamoto, I.; Nishibori, M. Histidine-rich glycoprotein plus zinc reverses growth inhibition of vascular smooth muscle cells by heparin. Cell Tissue Res. 2003, 312, 353-359. [CrossRef]

26. Crowe, J.; Masone, B.S.; Ribbe, J. One-step purification of recombinant proteins with the 6xHis tag and Ni-NTA resin. Mol. Biotechnol. 1995, 4, 247-258. [CrossRef]

27. Chao, A.; Jiang, N.; Yang, Y.; Li, H.; Sun, H. A Ni-NTA-based red fluorescence probe for protein labelling in live cells. J. Mater. Chem. B 2017, 5, 1166-1173. [CrossRef] [PubMed]

28. Khan, F.; He, M.; Taussig, M.J. Double-hexahistidine tag with high-affinity binding for protein immobilization, purification, and detection on Ni- nitrilotriacetic acid surfaces. Anal. Chem. 2006, 78, 3072-3079. [CrossRef]

29. El Alami, A.; Lagarde, F.; Huo, Q.; Zheng, T.; Baitoul, M.; Daniel, P. Acetylcholine and acetylcholinesterase inhibitors detection using gold nanoparticles coupled with dynamic light scattering. Sens. Int. 2020, 1, 100007. [CrossRef]

30. Arcas, A.S.; Jaramillo, L.; Costa, N.S.; Allil, R.C.S.; Werneck, M.M. Localized surface plasmon resonance-based biosensor on gold nanoparticles for Taenia solium detection. Appl. Opt. 2021, 60, 8137-8144. [CrossRef] 
31. Deka, J.; Mojumdar, A.; Parisse, P.; Onesti, S.; Casalis, L. DNA-conjugated gold nanoparticles based colorimetric assay to assess helicase activity: A novel route to screen potential helicase inhibitors. Sci. Rep. 2017, 7, 1-9. [CrossRef]

32. Xu, C.; Xu, K.; Gu, H.; Zhong, X.; Guo, Z.; Zheng, R.; Zhang, X.; Xu, B. Nitrilotriacetic acid-modified magnetic nanoparticles as a general agent to bind histidine-tagged proteins. J. Am. Chem. Soc. 2004, 126, 3392-3393. [CrossRef] [PubMed]

33. Li, Y.-C.; Lin, Y.-S.; Tsai, P.-J.; Chen, C.-T.; Chen, W.-Y.; Chen, Y.-C. Nitrilotriacetic acid-coated magnetic nanoparticles as affinity probes for enrichment of histidine-tagged proteins and phosphorylated peptides. Anal. Chem. 2007, 79, 7519-7525. [CrossRef] [PubMed]

34. Sosibo, N.M.; Tshikhudo, R.T.; Revaprasadu, N. Stable, hydrophilic nitrilotriacetic acid-capped gold monolayer protected clusters. In MRS Online Proceedings Library (OPL); Cambridge University Press: Cambridge, UK, 2007; Volume 1064.

35. Sanavio, B.; Scaini, D.; Grunwald, C.; Legname, G.; Scoles, G.; Casalis, L. Oriented immobilization of Prion protein demonstrated via precise interfacial nanostructure measurements. ACS Nano 2010, 4, 6607-6616. [CrossRef]

36. Schollbach, M.; Zhang, F.; Roosen-Runge, F.; Skoda, M.W.; Jacobs, R.M.; Schreiber, F. Gold nanoparticles decorated with oligo (ethylene glycol) thiols: Surface charges and interactions with proteins in solution. J. Colloid Interface Sci. 2014, 426, 31-38. [CrossRef]

37. Baselga, J.; Carbonell, X.; Castañeda-Soto, N.-J.; Clemens, M.; Green, M.; Harvey, V.; Morales, S.; Barton, C.; Ghahramani, P. Phase II study of efficacy, safety, and pharmacokinetics of trastuzumab monotherapy administered on a 3-weekly schedule. J. Clin. Oncol. 2005, 23, 2162-2171. [CrossRef] [PubMed]

38. Chen, H.; Kou, X.; Yang, Z.; Ni, W.; Wang, J. Shape-and size-dependent refractive index sensitivity of gold nanoparticles. Langmuir 2008, 24, 5233-5237. [CrossRef]

39. Cao, C.; Sim, S.J. Preparation of highly stable oligo (ethylene glycol) derivatives-functionalized gold nanoparticles and their application in LSPR-based detection of PSA/ACT complex. J. Nanosci. Nanotechnol. 2007, 7, 3754-3757. [CrossRef]

40. Han, J.-H.; Li, F.; Gunawan, R.C. Development of homogeneous plasmonic potency assay using gold nanoparticle immunocomplexes. J. Pharm. Biomed. Anal. 2020, 181, 113101. [CrossRef]

41. Yoshimura, K.; Maeda, M.; Kamiya, N.; Zako, T. Protein-functionalized gold nanoparticles for antibody detection using the darkfield microscopic observation of nanoparticle aggregation. Anal. Sci. 2020, 37, 507-511. [CrossRef]

42. Duan, Y.; Wu, W.; Zhao, Q.; Liu, S.; Liu, H.; Huang, M.; Wang, T.; Liang, M.; Wang, Z. Enzyme-antibody-modified gold nanoparticle probes for the ultrasensitive detection of nucleocapsid protein in SFTSV. Int. J. Environ. Res. Public Health 2020, 17, 4427. [CrossRef] 